\title{
Stereotactic radiosurgery in the treatment of parasellar meningiomas: long-term volumetric evaluation
}

\author{
Or Cohen-Inbar, MD, PhD, ${ }^{1,4}$ Athreya Tata, BA, ${ }^{1}$ Shayan Moosa, MD, ${ }^{1}$ Cheng-chia Lee, MD, ${ }^{2,3}$ and \\ Jason P. Sheehan, MD, PhD ${ }^{1}$
}

\begin{abstract}
'Department of Neurological Surgery, University of Virginia Health System, Charlottesville, Virginia; ${ }^{2}$ Neurological Institute, Taipei Veteran General Hospital; ${ }^{3}$ National Yang-Ming University, Taipei, Taiwan; and ${ }^{4}$ Department of Neurosurgery, Rambam Maimondes Health Care Campus, Haifa, Israel
\end{abstract}

OBJECTIVE Parasellar meningiomas tend to invade the suprasellar, cavernous sinus, and petroclival regions, encroaching on adjacent neurovascular structures. As such, they prove difficult to safely and completely resect. Stereotactic radiosurgery (SRS) has played a central role in the treatment of parasellar meningiomas. Evaluation of tumor control rates at this location using simplified single-dimension measurements may prove misleading. The authors report the influence of SRS treatment parameters and the timing and volumetric changes of benign WHO Grade I parasellar meningiomas after SRS on long-term outcome.

METHODS Patients with WHO Grade I parasellar meningiomas treated with single-session SRS and a minimum of 6 months of follow-up were selected. A total of 189 patients $(22.2 \%$ males, $n=42)$ form the cohort. The median patient age was 54 years (range 19-88 years). SRS was performed as a primary upfront treatment for $44.4 \%(n=84)$ of patients. Most $(41.8 \%, n=79)$ patients had undergone 1 resection prior to SRS. The median tumor volume at the time of SRS was $5.6 \mathrm{~cm}^{3}\left(0.2-54.8 \mathrm{~cm}^{3}\right)$. The median margin dose was $14 \mathrm{~Gy}$ (range 5-35 Gy). The volumes of the parasellar meningioma were determined on follow-up scans, computed by segmenting the meningioma on a slice-by-slice basis with numerical integration using the trapezoidal rule.

RESULTS The median follow-up was 71 months (range 6-298 months). Tumor volume control was achieved in $91.5 \%$ $(n=173)$. Tumor progression was documented in $8.5 \%(n=16)$, equally divided among infield recurrences $(4.2 \%, n=8)$ and out-of-field recurrences $(4.2 \%, n=8)$. Post-SRS, new or worsening CN deficits were observed in 54 instances, of which 19 involved trigeminal nerve dysfunction and were 18 related to optic nerve dysfunction. Of these, $90.7 \%(n=49)$ were due to tumor progression and only $9.3 \%(n=5)$ were attributable to SRS. Overall, this translates to a $2.64 \%(n=$ $5 / 189)$ incidence of direct SRS-related complications. These patients were treated with repeat SRS $(6.3 \%, n=12)$, repeat resection $(2.1 \%, n=4)$, or both $(3.2 \%, n=6)$. For patients treated with a margin dose $\geq 16 \mathrm{~Gy}$, the 2-, 4-, 6-, 8-, 10-, $12-$, and $15-y e a r$ actuarial progression-free survival rates are $100 \%, 100 \%, 95.7 \%, 95.7 \%, 95.7 \%, 95.7 \%$, and $95.7 \%$, respectively. Patients treated with a margin dose < $16 \mathrm{~Gy}$, had 2-, 4-, 6-, 8-, 10-, 12-, and 15-year actuarial progressionfree survival rates of $99.4 \%, 97.7 \%, 95.1 \%, 88.1 \%, 82.1 \%, 79.4 \%$, and $79.4 \%$, respectively. This difference was deemed statistically significant $(p=0.043)$. Reviewing the volumetric patient-specific measurements, the early follow-up volumetric measurements (at the 3-year follow-up) reliably predicted long-term volume changes and tumor volume control (at the 10-year follow-up) ( $p=0.029)$.

CONCLUSIONS SRS is a durable and minimally invasive treatment modality for benign parasellar meningiomas. SRS offers high rates of growth control with a low incidence of neurological deficits compared with other treatment modalities for meningiomas in this region. Volumetric regression or stability during short-term follow-up of 3 years after SRS was shown to be predictive of long-term tumor control.

https://thejns.org/doi/abs/10.3171/2016.11.JNS161402

KEY WORDS meningioma; stereotactic radiosurgery; Gamma Knife

ABBREVIATIONS ARE = adverse radiation event; $C N=$ cranial nerve; GKRS = Gamma Knife radiosurgery; LINAC = linear accelerator; PFS = progression-free survival; SRS = stereotactic radiosurgery.

SUBMITTED June 1, 2016. ACCEPTED November 7, 2016.

INCLUDE WHEN CITING Published online March 24, 2017; DOI: 10.3171/2016.11.JNS161402. 
$\mathrm{M}$ ENINGIOMAS are one of the most common types of intracranial tumors and account for $24 \%-33 \%$ of primary brain tumors. ${ }^{9,55}$ The majority of meningiomas are WHO Grade I, thought to arise from arachnoidal cap cells, and are typically slow-growing, well-circumscribed lesions with benign histopathology. A safe and complete resection, when feasible, constitutes the preferred treatment modality., $, 8,46$ The location of the tumor can significantly alter its clinical characteristics. In particular, parasellar meningiomas are a subset of skull base meningiomas in or around the sella turcica, thereby invading the suprasellar, cavernous sinus, and petroclival regions. ${ }^{6,7}$

Parasellar meningiomas tend to encroach on adjacent critical neurovascular structures and have proven difficult to safely and completely resect even with advanced skull base approaches and endoscopic or microscopic resection techniques. ${ }^{3,36}$ Because of such difficulty, open resection has been associated with variegated rates of complete resection and significant risks of procedure-related morbidity and mortality as well as delayed recurrence. Cranial nerve $(\mathrm{CN})$ deficits as well as internal carotid artery and cavernous sinus injuries prove detrimental to a patient's neurological function and quality of life. The incidence of temporary and permanent postoperative $\mathrm{CN}$ deficits is as high as $44 \%$ and $56 \%$, respectively, and operative mortality rates in some series have been reported to be as high as 9\% (median 3.6\%). ${ }^{1,33}$

Stereotactic radiosurgery (SRS) is a well-established alternative to resection of meningiomas, particularly for those located in the skull base or adjacent to critical neurovascular structures. For the past 3 decades, SRS has played a central role in the treatment of skull base parasellar meningiomas, as primary treatment, adjuvant treatment, or treatment for recurrence. ${ }^{51,52}$ Previous reports have shown an appealing benefit-risk ratio for SRS, with long-term tumor control rates of $92 \%-100 \%$ and acceptably low rates of associated morbidity and complications. ${ }^{15,19}$ Such tumor control rates, with 5- and 10-year actuarial rates of 91\% and $88 \%$, respectively, are comparable to those attained with Simpson Grade I microsurgical resection, which is often not feasible for skull base meningiomas. ${ }^{38,46}$

Evaluation of tumor control rates using simplified single-dimension diameter measurements may prove misleading for these lesions. The complex skull architecture of the parasellar area results in complex meningioma potential growth patterns, which are often missed when lesions are evaluated in only a single-dimension fashion. Lesion volumetric follow-up is recommended by many but used by few for follow-up because of technical constraints. ${ }^{6-8,19,23,48}$ In the current study, we reviewed the influence of presenting features, treatment parameters, and the timing and volumetric changes of benign WHO Grade I parasellar meningiomas after single-session SRS on long-term tumor control and other outcome parameters.

\section{Methods \\ Patient Population}

This is a retrospective analysis of a prospectively maintained database approved by the University of Virginia in- stitutional review board. The database was assessed for patients who harbored a benign meningioma involving the sellar and/or parasellar region and were treated between 1986 and 2014 with a single-session SRS utilizing the Gamma Knife at the University of Virginia Health System. Patients were included in the study if they had a minimum radiological and clinical follow-up time of 6 months $(\mathrm{n}=$ 189). Anterior optic apparatus dosing followed the strict published QUANTEC guidelines. If tumor architecture or proximity to the anterior optic apparatus precluded a safe single-session SRS treatment, these patients would typically undergo hypofractionated SRS and, as such, would be excluded from analysis. Patients harboring more than a single meningioma; those having a history of cancer, neurofibromatosis Type 2, or other genetic predispositions; and those with WHO Grade II or III meningioma were excluded. Patients were included in the cohort if they had clinical and imaging features consistent with a benign meningioma in the parasellar neuroanatomical region. Such features included an extraaxial location, avid and uniform contrast enhancement, dural attachment (i.e., a dural tail), and intratumoral calcification. Patients treated with upfront SRS by definition lacked a definitive tissue diagnosis of benign WHO Grade I meningioma.

The specific patient and tumor attributes are detailed in Tables 1-3. A total of 189 patients were included in the cohort; $22.2 \%$ were male $(\mathrm{n}=42)$. The median age was 54 years (range $19-88$ years), with $79.9 \%(\mathrm{n}=151)$ of patients being younger than or equal to 65 years. The most common neurological symptom was diplopia $(39.7 \%, \mathrm{n}=$ $75)$, followed by facial tactile sensation changes $(38.1 \%, \mathrm{n}$ $=72$ ), visual deterioration $(31.7 \%, \mathrm{n}=60)$, and headaches $(29.1 \%, \mathrm{n}=55)$. The most common $\mathrm{CN}$ deficit pre-SRS was oculomotor nerve palsy $(38.1 \%, \mathrm{n}=72)$, followed by trigeminal nerve deficits $(37 \%, \mathrm{n}=70)$, optic nerve damage $(27.5 \%, \mathrm{n}=52)$, and abducens nerve palsy $(25.9 \%, \mathrm{n}=$ 49). Pre-SRS pituitary deficiency (any axis) was noted in $4.2 \%(n=8)$ of patients (Table 2$)$.

SRS was performed as a primary upfront treatment for $44.4 \%(\mathrm{n}=84)$ of the patients, for a residual tumor after surgical debulking in $46.6 \%(n=88)$ of patients, and for tumor recurrence (after complete resection) in $7.9 \%$ ( $\mathrm{n}=$ $15)$ of patients. Of those patients who underwent a preSRS microsurgical resection, most $(41.8 \%, \mathrm{n}=79)$ had undergone a single resection, although some $(3.6 \%, \mathrm{n}=7)$ had undergone 3 or more attempts at microsurgical resection prior to SRS. The median interval between associated neurological symptoms and SRS was 11.5 months (range 0-290 months). The median tumor volume at the time of Gamma Knife radiosurgery (GKRS; Elekta, AB) was 5.6 $\mathrm{cm}^{3}$ (range $0.2-54.8 \mathrm{~cm}^{3}$ ). Volume was determined using the GammaPlan software (Elekta, AB) or the ImageJ software (National Institutes of Health) as previously described..$^{48}$

\section{Radiosurgical Technique}

The details of SRS (GKRS) performed at our center have been reported previously. ${ }^{52}$ The Leksell Gamma Knife Unit Model U was used from May 1989 to July 2001, followed by the use of the Model C from July 2001 to September 2007. The Gamma Knife Perfexion model 
TABLE 1. Demographic characteristics in 189 patients with parasellar meningiomas

\begin{tabular}{|c|c|}
\hline Characteristics & Value \\
\hline \multicolumn{2}{|l|}{ Sex } \\
\hline Male & $42(22.2)$ \\
\hline Female & $147(77.8)$ \\
\hline \multicolumn{2}{|l|}{ Age, yrs } \\
\hline Median (range) & $54(19-88)$ \\
\hline$\leq 65$ & $151(79.9)$ \\
\hline$>65$ & $38(20.1)$ \\
\hline \multicolumn{2}{|l|}{ Tumor vol, $\mathrm{cm}^{3}$} \\
\hline Median (range) & $5.6(0.2-54.8)$ \\
\hline$<4$ & $64(33.9)$ \\
\hline $4-10$ & $85(45.0)$ \\
\hline$>10$ & $40(21.2)$ \\
\hline Previous resection & $105(55.6)$ \\
\hline 1 & $79(41.8)$ \\
\hline 2 & $19(10.1)$ \\
\hline 3 & $5(2.6)$ \\
\hline$>4$ & $2(1)$ \\
\hline \multicolumn{2}{|l|}{ Indication for GKRS } \\
\hline Upfront & $84(44.4)$ \\
\hline Residual & $88(46.6)$ \\
\hline Recurrence & $15(7.9)$ \\
\hline Unknown & $2(1.1)$ \\
\hline Median period btwn symptoms \& GKRS (range) & $11.5(0-290)$ \\
\hline \multicolumn{2}{|l|}{ GKRS parameters } \\
\hline Median radiation vol (range), $\mathrm{cm}^{3}$ & $5.4(0.3-105)$ \\
\hline \multicolumn{2}{|l|}{ Margin dose, Gy } \\
\hline Median (range) & $14(5-35)$ \\
\hline$<16$ & $155(82)$ \\
\hline$\geq 16$ & $34(18)$ \\
\hline \multicolumn{2}{|l|}{ Max dose, Gy } \\
\hline Median (range) & $32(12-70)$ \\
\hline$<32$ & $94(49.7)$ \\
\hline$\geq 32$ & $95(50.3)$ \\
\hline Median isodose line, \% (range) & $50(21-60)$ \\
\hline Median follow-up in mos (range) & $71(6-298)$ \\
\hline
\end{tabular}

was used after September 2007. The Kula software (Elekta, AB) was used for dose planning until June 1994, and then was replaced by GammaPlan software. The treating surgeon, in consultation with a medical physicist and radiation oncologist, devised the radiosurgical parameters and dose plans. Although there was some variation in the details of stereotactic imaging for radiosurgical planning varied over time, planning usually consisted of a pre- and postcontrast, volumetrically acquired gradient echo pulse sequences reconstructed into axial and coronal image stacks. Voxel sizes varied from $1 \mathrm{~mm} \times 1 \mathrm{~mm} \times 3 \mathrm{~mm}$ to $1 \mathrm{~mm} \times 1 \mathrm{~mm} \times 1.3 \mathrm{~mm}$. When an MRI study could not be obtained because of medical contraindications (e.g., a
TABLE 2. Neurological symptoms in 189 patients

\begin{tabular}{lcc}
\hline & \multicolumn{2}{c}{ No. of Patients (\%) } \\
\cline { 2 - 3 } Neurological Symptom & $\begin{array}{c}\text { Impaired } \\
\text { Pre-GKRS }\end{array}$ & $\begin{array}{c}\text { Deteriorated } \\
\text { Post-GKRS }\end{array}$ \\
\hline Headache & $55(29.1)$ & $14(7.4)$ \\
\hline Vision deterioration & $60(31.7)$ & $22(11.6)$ \\
\hline Diplopia & $75(39.7)$ & $15(7.9)$ \\
\hline Ptosis & $40(21.2)$ & $5(2.6)$ \\
\hline Face & & \\
\hline Tactile sensation changes & $72(38.1)$ & $12(6.3)$ \\
\hline Numbness/hypesthesia & $41(21.7)$ & $16(8.5)$ \\
\hline Facial pain & $13(6.9)$ & $3(1.6)$ \\
\hline Facial paresthesia & $7(3.7)$ & $1(0.5)$ \\
\hline Multiple sensation & $11(5.8)$ & $2(1.1)$ \\
\hline Hormone dysfunction & $8(4.2)$ & $1(0.5)$ \\
\hline CN deficits & & \\
\hline Optic nerve & $52(27.5)$ & $18(9.5)$ \\
\hline Oculomotor nerve & $72(38.1)$ & $9(4.8)$ \\
\hline Trochlear nerve & $22(11.6)$ & $5(2.6)$ \\
\hline Trigeminal nerve & $70(37.0)$ & $19(10.1)$ \\
\hline Abducens nerve & $49(25.9)$ & $3(1.6)$ \\
\hline
\end{tabular}

* There were 54 incidences of $\mathrm{CN}$ deficits because some patients had more than 1 deficit. Percentages are based on the number of patients.

cardiac pacemaker), a thin-slice $(\leq 1.0 \mathrm{~mm})$ stereotactic CT scan (with and without contrast) was obtained.

The median margin dose used in this cohort was 14 Gy (range 5-35 Gy). The majority of radiosurgical plans used margin doses lower than 16 Gy $(82 \%, \mathrm{n}=155)$. The median maximum dose used was 32 Gy (range 12-70 Gy). The maximum dose distribution was roughly equal, with $49.7 \%(n=94)$ of patients treated with a maximum dose equal to or higher than 32 Gy compared with $50.3 \%$ ( $\mathrm{n}=$ 95) of patients treated with a margin dose lower than 32 Gy. The median isodose line used was 50\% (range 21\%$60 \%$ ). Radiosurgical parameters are detailed in Table 1.

\section{Clinical and Radiological Assessment After GKRS}

After SRS, clinical examination was performed in all patients. Imaging follow-up occurred approximately 2 times a year in the first 2 years and then yearly thereafter. An attending neurosurgeon and neuroradiologist at the University of Virginia reviewed all neuroimages. Visible tumors were deemed to have had a stable response if the volumetry was within $10 \%$ of the original volume, to have increased in size if the volumetry was greater than $10 \%$ of the original volume, and to have decreased if it was at least $10 \%$ smaller than its original volume..$^{48}$ Adverse radiation effects (AREs), were defined as any post-SRS perilesional hyperintensity noted on T2-weighted or FLAIR MRI sequences.

\section{Meningioma Volumetric Assessment}

The volumes of the parasellar meningiomas were determined for each imaging data set available for patients 
TABLE 3. Tumor outcomes, AREs, and further intervention

\begin{tabular}{cc}
\hline \multicolumn{1}{c}{ Variable } & No. of Patients (\%) \\
\hline Tumor response $^{*}$ & \\
\hline Regression (vol decrease $>10 \%)$ & $91(48.1)$ \\
\hline Stable (vol change $<10 \%)$ & $82(43.4)$ \\
\hline Progression (vol increase $>10 \%)$ & $16(8.5)$ \\
\hline Infield recurrence & $8(4.8)$ \\
\hline Out-of-field recurrence & $8(4.2)$ \\
\hline Radiation-induced changes & $2(1.1)$ \\
\hline AREs & $0(0)$ \\
\hline Radiation necrosis & $10(5.3)$ \\
\hline Further intervention & $12(6.3)$ \\
\hline Resection & $4(2.1)$ \\
\hline Repeat GKRS & $8(4.2)$ \\
\hline For the same tumor & $4(2.1)$ \\
\hline For a different tumor &
\end{tabular}

* Overall post-GKRS neurological improvement: $39.2 \%$ improved, $46.0 \%$ remained stable, and $14.8 \%$ deteriorated.

in a longitudinal fashion. The meningioma volume was determined from postcontrast T1-weighted images used for the SRS treatment plan. Volumes were computed by segmenting the meningioma on a slice-by-slice basis with numerical integration using the trapezoidal rule. ${ }^{37}$ The ImageJ software was used for contouring and volume computations.

\section{Statistical Analysis}

Statistical analysis was performed using a commercially available statistical package (version 20, IBM SPSS, IBM Corp.). Descriptive statistics were calculated for all variables, including mean, median, standard deviation, and frequency distributions as appropriate. Multivariate logistic regression was used to evaluate clinical covariates hypothesized to predict tumor control and post-GKRS improvement, including age, tumor volume at time of GKRS, sex, peritumoral edema, and tumor location. Kaplan-Meier analysis was performed for tumor control and post-GKRS improvement. All statistical tests were 2-sided unless described otherwise; $\mathrm{p}<0.05$ was considered statistically significant.

\section{Results}

\section{Tumor Control}

The specific tumor control parameters are detailed in Table 3. With a median follow-up time of 71 months (range 6-298 months), overall tumor volume control was achieved in $91.5 \%(\mathrm{n}=173)$ of patients. Of these, $48.1 \%$ ( $=91$ ) showed tumor volume regression (volume decrease $>10 \%)$, and $43.4 \%(\mathrm{n}=82)$ showed tumor volume stability (volume change $<10 \%$ ). At last follow-up, tumor progression was documented in $8.5 \%(\mathrm{n}=16)$ of patients. This figure was equally divided among infield recurrences $(4.2 \%, \mathrm{n}=8)$ and out-of-field recurrences $(4.2 \%, \mathrm{n}=8)$.

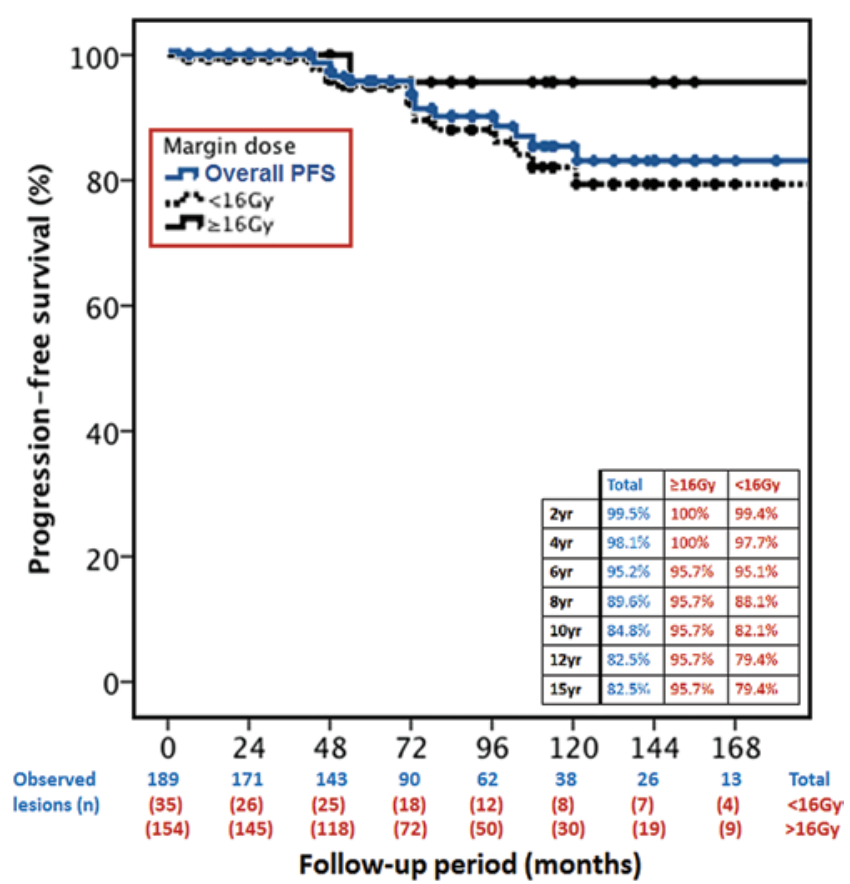

FIG. 1. Kaplan-Meier curve presenting overall actuarial PFS as well as separated based on margin dose < 16 Gy vs $\geq 16$ Gy. Refer to text. Figure is available in color online only.

The overall 2-, 4-, 6-, 8-, 10-, 12-, and 15-year actuarial progression-free survival (PFS) rates were 99.5\%, 98.1\%, $95.2 \%, 89.6 \%, 84.8 \%, 82.5 \%$, and $82.5 \%$, respectively (Fig. 1). AREs were noted in $1.1 \%(\mathrm{n}=2)$. Radiation necrosis was not noted in this cohort. An example patient is presented in Fig. 2.

\section{Clinical and Neurological Outcome}

The most common post-SRS neurological symptoms were visual deterioration $(11.6 \%, \mathrm{n}=22)$, followed by facial numbness $(8.5 \%, \mathrm{n}=16)$, diplopia $(8.3 \%, \mathrm{n}=15)$, and headache $(7.4 \%, n=14)$ (Table 2$)$. All cases of visual deterioration occurred in patients with pre-SRS visual deficits. $\mathrm{CN}$ stability and improvement were logged together. PostSRS, new or worsening $\mathrm{CN}$ deficits were observed in 54 instances (not patients, since a single patient may have developed multiple post-SRS CN deficits). Of these reports, $90.7 \%$ such instances $(n=49)$ were noted as secondary to tumor progression post-SRS and 9.3\% were defined as a complication of SRS (all CNs). The most common postSRS CN damaged was the trigeminal nerve $(10.1 \%, \mathrm{n}=$ $19)$, followed by the optic nerve $(9.5 \%, \mathrm{n}=18)$ and the oculomotor nerve $(4.8 \%, \mathrm{n}=9)$. Post-SRS pituitary hormone deficiency (any axis) was noted in $0.5 \%(\mathrm{n}=1)($ Table 2$)$.

\section{Treatment of Progression or Recurrence}

Overall, 8.5\% $(\mathrm{n}=16)$ of patients who exhibited tumor progression after the first SRS received further care, as detailed in Table 3. Repeat SRS was performed in 4 patients (2.1\%) for an infield recurrence, having a median tumor volume growth from $1.8 \mathrm{~cm}^{3}$ to $6.4 \mathrm{~cm}^{3}(63.4 \%)$ during an interval time of 45 months (range 25-132 months), utiliz- 


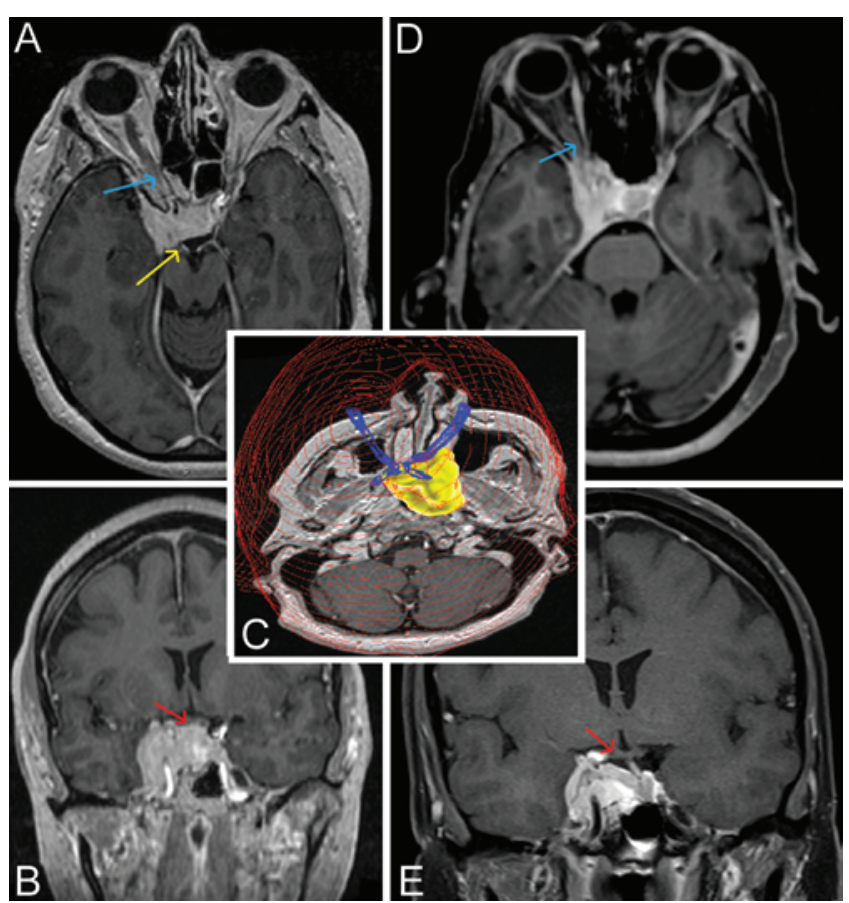

FIG. 2. Example patient. $A$ and B: Pre-SRS axial (A) and coronal (B) T1-weighted MR images with gadolinium showing a right parasellar meningioma invading the cavernous sinus, compressing the anterior optic apparatus (blue and red arrows) and the oculomotor nerve (yellow arrow). C: GKRS treatment plan. The optic nerves and chiasm are contoured in blue. The tumor volume was $15.71 \mathrm{~cm}^{3}$, treated with a margin dose of 16 Gy. D and E: Post-SRS follow-up axial (D) and coronal (E) T1-weighted MR images with gadolinium obtained 48 months post-SRS, showing tumor volume control and less compression of the anterior optic apparatus (blue and red arrows). Of note, the patient was legally blind at the time of SRS from prior growth and surgical intervention. As such, optic apparatus dosing was not a concern. Figure is available in color online only.

ing a median margin dose of 16 Gy (range 10-25 Gy). Of these 4 patients, $75 \%(n=3)$ attained local tumor control after repeat SRS. One patient developed a new neurological deficit after repeat SRS. Repeat SRS for an out-offield recurrence was performed in $4.2 \%(\mathrm{n}=8)$ additional patients, with a median tumor volume of $2.4 \mathrm{~cm}^{3}$ (range $1.2-5.8 \mathrm{~cm}^{3}$ ) during an interval time of 48 months (range 22-110 months), utilizing a median margin dose of $14 \mathrm{~Gy}$ (range $12-28 \mathrm{~Gy})$. Of these 8 patients, $88 \%(\mathrm{n}=7)$ attained local tumor control after repeat SRS at last follow-up.

Post-SRS resection was performed in 5.3\% $(\mathrm{n}=10)$ of patients. This figure includes $2.1 \%(\mathrm{n}=4)$ patients who were treated only with post-SRS resection and 3.2\% (n $=6)$ patients in whom repeat SRS failed as well. Histopathological examination of the resected tumor confirmed a WHO Grade I benign meningioma. A median tumor volume growth from $4.6 \mathrm{~cm}^{3}$ to $10.8 \mathrm{~cm}^{3}$ (82.8\%) was noted during an interval time of 47 months (range 13-178 months). Of these 10 patients, $60 \%(n=6)$ attained local tumor control after repeat SRS at last follow-up, 30\% (n $=3$ ) developed some new permanent neurological deficit after the resection, and $10 \%(\mathrm{n}=1)$ developed a new $\mathrm{CN}$ deficit (Table 4).

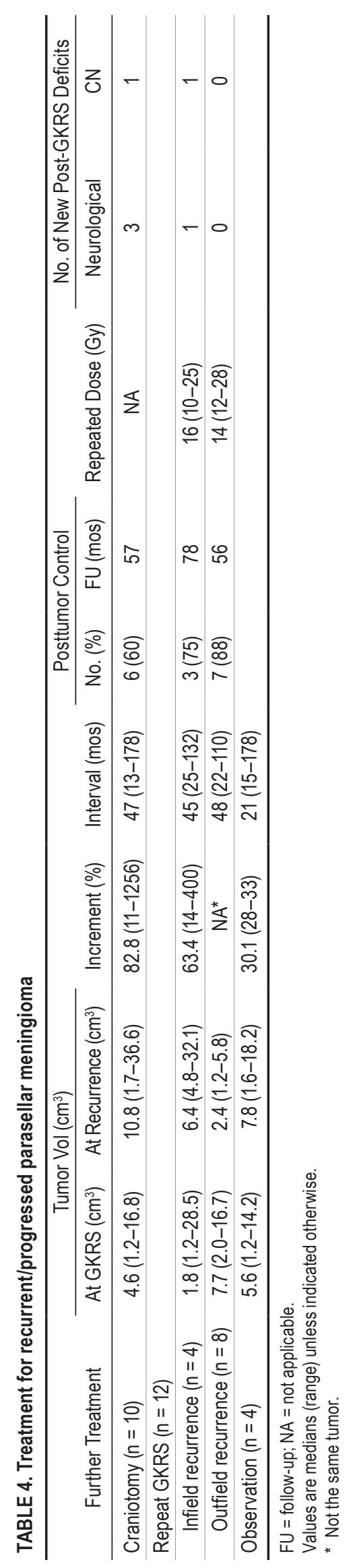




\section{Pre-SRS Factors Influencing Tumor Progression}

We evaluated factors related to tumor progression (i.e., tumor control) (Table 5 and Fig. 1). Tumor volume at the time of initial SRS was noted to influence the rate of local failure in both univariate and multivariate analyses, when grouped to lesions $>14 \mathrm{~cm}^{3}$ (HR 1.914 [95\% CI 1.3252.538], $\mathrm{p}=0.044$; and HR 1.832 [95\% CI 1.134-2.594], $\mathrm{p}$ $=0.048$, respectively).

A tumor margin dose lower than 16 Gy (HR 0.329 [95\% CI 0.027-0.983], $\mathrm{p}=0.043$ ) was noted as predictive of tumor progression on multivariate analysis. As shown in Fig. 1, for patients treated with a margin dose $\geq 16 \mathrm{~Gy}$, the 2-, 4-, 6-, 8-, 10-, 12-, and 15-year actuarial PFS rates are $100 \%, 100 \%, 95.7 \%, 95.7 \%, 95.7 \%, 95.7 \%$, and $95.7 \%$, respectively. Patients treated with a margin dose $<16 \mathrm{~Gy}$, had 2-, 4-, 6-, 8-, 10-, 12-, and 15-year actuarial PFS rates of $99.4 \%, 97.7 \%, 95.1 \%, 88.1 \%, 82.1 \%, 79.4 \%$, and $79.4 \%$, respectively. This difference was deemed statistically significant $(\mathrm{p}=0.043)$.

\section{Tumor Volume Changes as a Predictor}

Individual patient's volumetric data are presented in Fig. 3. Patient's tumor volume changes (relative to the $100 \%$ volume at the time of initial SRS) during the followup period are shown per patient. As depicted in Fig. 3, the median change in tumor volume manifests mean tumor volume control and regression. Reviewing the volumetric patient-specific measurements, an important role for early follow-up measurements arises. As depicted in Fig. 4, the early follow-up volumetric measurements (at the 3-year follow-up) reliably predicted long-term volume changes and tumor volume control (at the 10-year follow-up) ( $\mathrm{p}=$ $0.029)$.

\section{Discussion}

Neurosurgeons face clinical challenges in the management of parasellar meningiomas. The difficulties these tumors present are related to the potential morbidity associated with the surgical approach, tumor exposure and dis- section, their consistency (frequently firm) and vascularity, and their localization to critical neuroendocrine, vascular, and $\mathrm{CN}$ structures. These features usually taint surgical outcomes and make complete resection difficult. ${ }^{3,36}$ High reported rates of procedure-related morbidity and mortality, ${ }^{2,5,21,30}$ as well as high rates of delayed recurrence after partial resection, ${ }^{21,25,33,40,44,53}$ make resection a less appealing option. With increasing availability and reduced cost of imaging, these tumors are now being diagnosed at an earlier stage and smaller relative size, producing minimal symptoms. In these cases, the decision to undertake a potentially crippling surgery is even less appealing for both the patient and the surgeon.

\section{Stereotactic Radiosurgery for Parasellar Meningiomas}

With the addition of SRS to the armamentarium a few decades ago, aggressive resection and fractionated radiation therapy are less frequently considered for the treatment of parasellar meningiomas. Performing early SRS for smaller-volume tumors or subtotal resection followed by SRS (the so-called adoptive hybrid surgery) for largervolume tumors that encroach on adjacent structures and cause a symptomatic mass effect has taken a central role. Authors of a recent meta-analysis of patients who had undergone treatment for cavernous sinus meningioma reported that surgical debulking followed by SRS resulted in better tumor control rates than surgery alone, regardless of extent of resection..$^{54}$ In another study, the authors reported a significantly higher rate of cranial neuropathy for patients who had undergone resection higher than for patients who had undergone SRS alone. ${ }^{44}$

Clinical and radiological evidence demonstrating that a lesion is a benign WHO Grade I meningioma leads to selection of SRS as the primary treatment modality. Spiegelmann et al ${ }^{49}$ reported a cohort of radiologically diagnosed meningiomas treated with SRS, with a $98 \%$ tumor control rate. ${ }^{49}$ In their cohort of 219 patients with imagingdiagnosed meningiomas, a detailed history, clinical examination, and careful review of the neuroimaging studies, Flickinger et al. reported a 10-year actuarial misdiagnosis

TABLE 5. Prognostic factors associated with local failure (Cox regression)

\begin{tabular}{|c|c|c|c|c|c|c|}
\hline \multirow[b]{2}{*}{ Factors } & \multicolumn{3}{|c|}{ Univariate } & \multicolumn{3}{|c|}{ Multivariate } \\
\hline & $\mathrm{p}$ Value & $H R^{*}$ & $95 \% \mathrm{Cl}$ & p Value & $\mathrm{HR}^{*}$ & $95 \% \mathrm{Cl}$ \\
\hline Age & 0.551 & 1.412 & $0.455-4.383$ & & & \\
\hline Sex & 0.254 & 0.540 & $0.188-1.556$ & & & \\
\hline Tumor vol $\left(\mathrm{cm}^{3}\right)$ & 0.075 & & & & & \\
\hline $4-14$ & 0.060 & 1.883 & $0.995-2.729$ & 0.072 & 2.272 & $0.834-3.593$ \\
\hline$>14$ & 0.044 & 1.914 & $1.325-2.538$ & 0.048 & 1.832 & $1.134-2.594$ \\
\hline Margin dose $†$ & 0.130 & 0.276 & $0.036-2.088$ & 0.043 & 0.329 & $0.027-0.983$ \\
\hline Maximum dose & 0.940 & 1.038 & $0.386-2.794$ & & & \\
\hline Indication for GKRS & 0.930 & & & & & \\
\hline Residual & 0.502 & 0.713 & $0.266-1.914$ & & & \\
\hline Recurrence & 0.987 & 0.000 & $0.000-0.000$ & & & \\
\hline Interval btwn symptoms \& GKRS & 0.596 & 0.996 & $0.983-1.010$ & & & \\
\hline
\end{tabular}




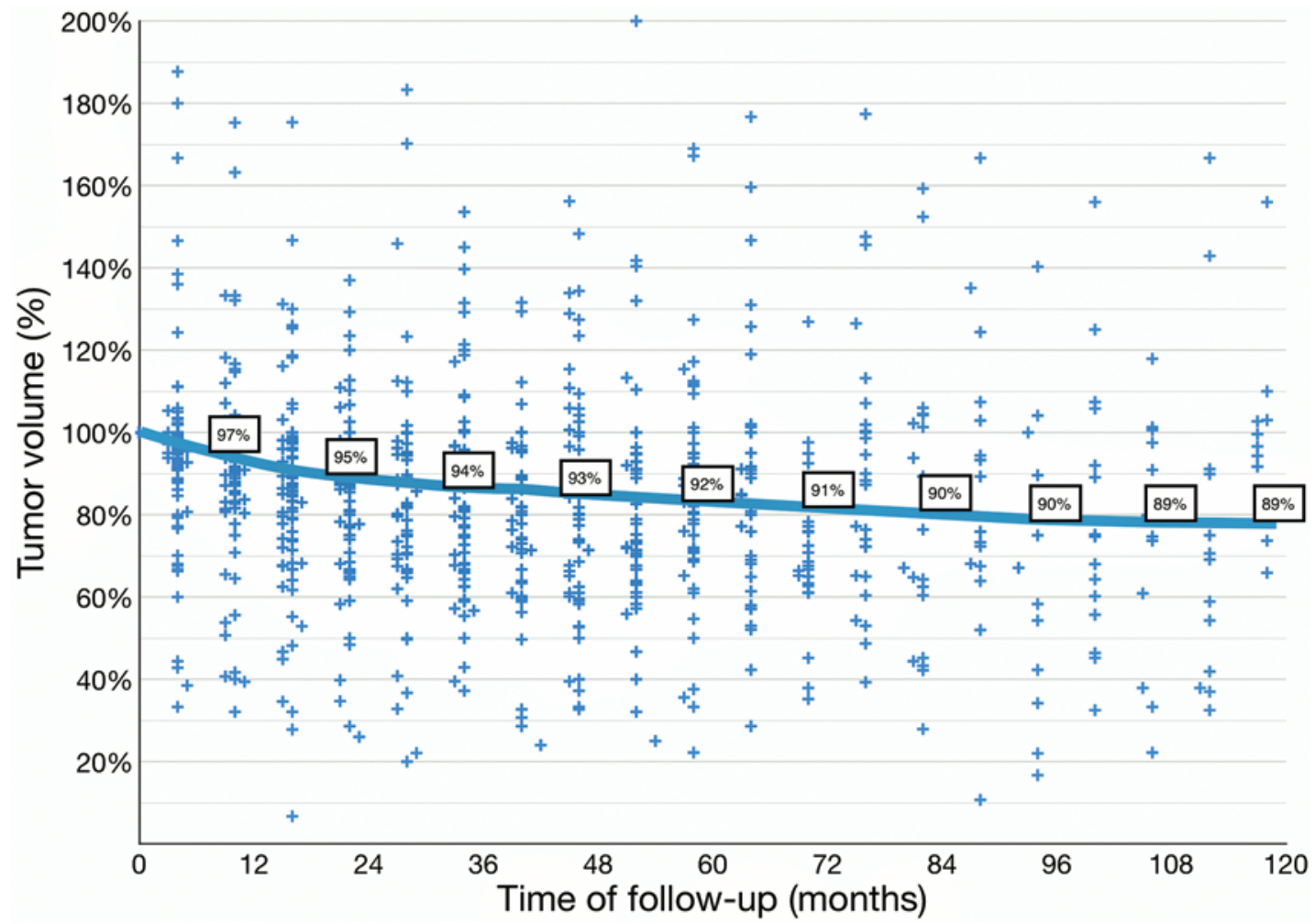

FIG. 3. Individual patient's volumetric data. Changes (\%) in tumor volume during the follow-up period are shown. The median change is depicted as a line with numeric values (100\% refers to the tumor volume at the time of SRS), showing an overall tumor control. Refer to text. Figure is available in color online only.

rate of $2.3 \% \pm 1.4 \%$ and an actuarial tumor control rate of be $93.2 \% \pm 2.7 \%$ at 10 years post-SRS. ${ }^{14} \mathrm{~A}$ multitude of reports from past decades did not find any differences in terms of tumor control or neurological outcomes between patients whose WHO Grade I meningioma diagnosis was confirmed with histological examination and those whose diagnosis was based on in patients receiving a diagnosis via neuroimaging findings and clinical features alone. ${ }^{6-8,14,44}$

Table 6 summarizes important reported series of parasellar and other skull base meningiomas treated with single-session SRS, followed for long periods of time (up to 102.5 months). ${ }^{7}$ There is a wide range of long-term clinical outcomes after SRS for parasellar meningiomas in the available literature. Neurological improvement rates vary from $8 \%$ to $66 \%$; reported post-SRS complication rates vary from $3 \%$ to $40 \%$. 10,12,13,18,23,27-29,34,51,56 Among published series with a cohort of 100 or more patients, rates of significant long-term complications (range 0\%-16\%) when the margin doses ranged from 12 to 15 Gy. ${ }^{10,12,13,18,27-29,34,56}$ Sughrue et al. ${ }^{54}$ reported pooled cranial neuropathy rates for patients undergoing microsurgical resection and SRS alone were $59.6 \%$ (95\% CI 50.3\%-67.5 and $25.7 \%$ (95\% CI $11.5 \%-38.9 \%)(\mathrm{p}<0.05) .{ }^{54}$ In a multicenter study we reported that the risk of any new or worsening cranial neuropathy occurring after GKRS was $9.6 \%$. We also found that the chance of improvement of pre-GKRS CN dysfunction after GKRS was 34\%. New or progressive dysfunction after GKRS were most commonly found in CNs II and $\mathrm{V}^{44}$ Of note, we reported SRS-induced optic nerve dysfunction in some patients in whom a maximum dose of 8 Gy or less (i.e., a "safe" dose) was delivered to the optic apparatus. Despite this low dose, some patients will experience visual decline. ${ }^{44}$ Overall, the data in Table 6 are in agreement with those of other treatment options and

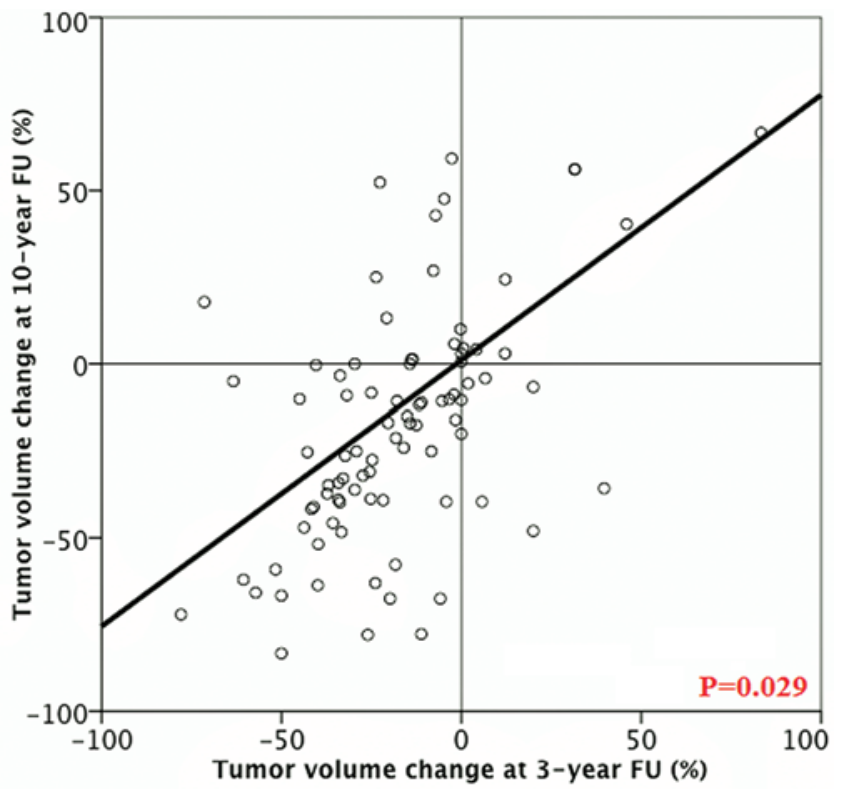

FIG. 4. The correlation between tumor volume changes (\%) at 3 and 10 years post-SRS follow-up (FU). A strong linear correlation is shown $(p=$ 0.029 ). Figure is available in color online only. 
TABLE 6. Parasellar and skull base meningiomas treated with SRS, literature review

\begin{tabular}{|c|c|c|c|c|c|c|c|c|}
\hline Authors \& Year & No. of Patients & $\begin{array}{c}\mathrm{FU} \\
(\mathrm{mos})^{*}\end{array}$ & Tumor Vol $\left(\mathrm{cm}^{3}\right)^{*}$ & $\begin{array}{l}\mathrm{MD} \\
(\mathrm{Gy})^{*}\end{array}$ & $\begin{array}{l}\text { Actuarial Tumor } \\
\text { Control Rate }(\%) \dagger\end{array}$ & $\begin{array}{c}\% 1 s t \\
\text { Treatment }\end{array}$ & $\begin{array}{c}\text { New CN } \\
\text { Deficit (\%) }\end{array}$ & $\begin{array}{c}\text { Morbidity } \\
(\%)\end{array}$ \\
\hline Duma et al., 1993 & 34 & $26 \ddagger$ & 5.17 & $16 \ddagger$ & $100[2]$ & 17.6 & 2.9 & 8.8 \\
\hline Hudgins et al., 1996 & 100 & NR & 14 & 15 & $91,97 \S$ & & NR & 12 \\
\hline Chang \& Adler, 1997 (LINAC) & 55 & 48 & 7.33 & 18.3 & 98 [2] & 32.7 & 3.6 & 7.2 \\
\hline Morita et al., 1999 & 88 & $35 \ddagger$ & $10 \ddagger$ & $16 \ddagger$ & $100[2], 95[5]$ & 37.5 & 10.2 & 11.4 \\
\hline Liscák et al., 1999 & 67 & $19 \ddagger$ & $7.8 \ddagger$ & $12 \ddagger$ & NR & NR & NR & NR \\
\hline Roche et al., 2000 & 80 & $30.5 \ddagger$ & 5.8 & 14 & $93[5]$ & 62.5 & 2.5 & 3.8 \\
\hline Nicolato et al., 2001 & 57 & $28.7 \ddagger$ & 5.9 & 15.2 & $88.9[5]$ & 56.5 & 0 & 0 \\
\hline Shin et al., 2001 & 40 & $42 \ddagger$ & $4.3 \ddagger$ & $18 \ddagger$ & $86.4[3], 82.3$ [10] & 30 & 0 & 0 \\
\hline Lee et al., 2002 & 159 & $35 \ddagger$ & $6.5 \ddagger$ & $13 \ddagger$ & $93[5], 93[10]$ & 52.2 & 4.4 & 6.3 \\
\hline Nicolato et al., 2002 & 156 & $48.9 \ddagger$ & $8.3 \ddagger$ & 14.6 & $96.5[5]$ & 48.1 & 0 & 0.6 \\
\hline Eustacchio et al., 2002 & 121 & 82 & 6.8 & 13 & 97.8 & NR & NR & 6.7 \\
\hline $\begin{array}{l}\text { Spiegelmann et al., } 2002 \\
\text { (LINAC) }\end{array}$ & 42 & $38 \ddagger$ & $8.2 \ddagger$ & 14 & $97.5[3 \& 7]$ & 73.8 & 7.1 & 7.1 \\
\hline Iwai et al., 2003 & 43 & $49.4 \ddagger$ & 14.7 & 11 & $92[5]$ & 46.5 & 0 & 0 \\
\hline Selch et al., 2004 (LINAC) & 45 & $36 \ddagger$ & $14.5 \ddagger$ & $50.4 \ddagger$ & 97.4 [3] & 35.6 & 0 & 2.2 \\
\hline Kreil et al., 2005 & 200 & $95 \ddagger$ & $6.5 \ddagger$ & $12 \ddagger$ & $98.5[5], 97.2[10]$ & 50.5 & 0.5 & 0.5 \\
\hline Pollock \& Stafford, 2005 & 49 & 58 & 10.2 & 15.9 & 100 & 100 & 8.2 & 10.2 \\
\hline Feigl et al., 2007 & 211 & 24 & $6.5 \ddagger$ & 13.8 & 98 [1], 95 [2], 86.3 [4] & 41.7 & 5.2 & 6.6 \\
\hline Hasegawa et al., 2007 & 115 & $62 \ddagger$ & 14 & 13 & $94[5], 92[10]$ & 42.6 & $0.8 \rrbracket$ & 4.3 \\
\hline Han et al., 2008 & 63 & 77 & 6.5 & 12.6 & $90[5]$ & 68.3 & NR & 9.5 \\
\hline Iwai et al., 2008 & 108 & 86.1 & 8.1 & 12 & $93[5], 83$ [10] & 42.6 & 2.8 & 6.5 \\
\hline Kondziolka et al., 2008 & $972^{* *}$ & 48 & 7.4 & 14 & 97 [5], 87 [10 \& 15] & 55.1 & 1.2 & 9.1 \\
\hline Ganz et al., 2009 & 97 & 53 & 15.9 & 11.6 & $100[2]$ & NR & NR & 3 \\
\hline Igaki et al., 2009 & 98 & $53.2 \ddagger$ & 3.9 & 16 & $86.9[5], 78.9[10]$ & 35.7 & 1.0 & 1.0 \\
\hline Kimball et al., 2009 (LINAC) & 55 & $50 \ddagger$ & $5.9 \ddagger$ & 12.9 & $100[5], 98[10]$ & 78.2 & 0 & 0 \\
\hline Takanashi et al., 2009 & 101 & 52 & 7.1 & 13.2 & 97 & NR & NR & 0 \\
\hline Skeie et al., 2010 & 100 (40††, 60‡‡) & 82 & 7.39 (6.8††, 7.8‡‡) & 12.4 & 98.9 [1], 94.2 [5], 91.6 [10] & 40 & 2 & 5 \\
\hline Williams et al., 2011 & 138 & 84 & 7.5 & 13.7 & $95.4[5], 69[10]$ & 39.1 & 10.1 & 10.1 \\
\hline Starke et al., 2012 & 255 & 78 & 5.0 & 14 & 99 [3], 96 [5], 79 [10] & 42.7 & 8.6 & 11.0 \\
\hline Cohen-Inbar et al., $2016^{7}$ & 135 & $102.5 \ddagger$ & $4.7 \ddagger$ & $15 \ddagger$ & $100[5], 88.1[10]$ & 36.3 & 14.8 & 31.9 \\
\hline \multicolumn{9}{|c|}{$\begin{array}{l}\text { MD = margin dose; NR = not reported. } \\
\text { * Values are means unless otherwise noted. } \\
\text { † Numbers in brackets represent the actuarial tumor control years. } \\
\text { ‡ Median values. } \\
\S \text { For lesions smaller than } 3 \mathrm{~cm} \text {. } \\
\text { I New and worsened post-GKRS CN deficits are reported together, not differentiated. } \\
{ }^{* *} \text { Not specific to skull base (the majority are). } \\
\text { †† Upfront SRS. } \\
\text { 政 SRS for postsurgical residual tumor. }\end{array}$} \\
\hline
\end{tabular}

the natural history of parasellar meningioma ${ }^{44}$ manifesting the appealing risk-to-benefit ratio offered by SRS for these challenging lesions.

$\mathrm{CN}$ dysfunction is most commonly seen in patients with parasellar or other skull base meningiomas treated with SRS. The most significant factor in $\mathrm{CN}$ deficit development was shown to be the length (volume) of the nerve irradiated, rather than the volume of tumor or the maximal dose. Tishler et al ${ }^{57}$ noted that the maximum doses delivered to CNs were associated with neurological deficits in 29 patients after linear accelerator (LINAC) SRS and 33 patients after GKRS. Doses up to 40 Gy were shown to be safe for the $\mathrm{CN}$ in the parasellar region. ${ }^{57}$ In treating patients with parasellar and sellar tumor histologies, we have delivered doses of 20-30 Gy to the CNs in the parasellar region with only rare complications..$^{43,44}$

We report on a cohort of 189 patients harboring parasellar meningiomas that were treated with single-session SRS and monitored with clinical, radiographic, and volumetric measurements. We observed superior tumor control rates when parasellar meningiomas were treated with a margin dose of $16 \mathrm{~Gy}$ or more. Also, nearly half the tumors (48.1\%) treated had regressed at last follow-up. Most importantly, the volumetric response of the tumor at 3 
years after initial GKRS was predictive of the long-term response seen at 10 years. Thus, the SRS results appear durable, and a favorable response at 3 years is an early predictor of a durable and likely successful long-term outcome (Fig. 4). Nevertheless, we still recommend some degree of longitudinal follow-up in all meningioma patients, regardless of whether conservative management or some form of treatment (e.g., resection or SRS) is employed.

\section{Study Limitations}

The limitations of this study include those inherent to the nature of retrospective data analysis. Patients treated with upfront SRS by definition lacked a definitive tissue diagnosis of benign WHO Grade I meningioma. The parasellar region is sizeable, and its definition may differ somewhat among authors in terms of extent of tumor involvement. This region encompasses different discrete locations, each with a finite natural history and discrete responses to radiosurgery. In addition, patient selection bias may have affected the use of upfront radiosurgery, resection, radiation therapy, and salvage radiosurgery based on other medical social and patient related parameters. The validity may be limited by patient selection bias inherent to our treatment algorithms. Patients who developed postradiosurgery complications were monitored more closely and had more frequent imaging and clinical evaluations, and thus might be overrepresented in this cohort. Comorbidities developing during the follow-up period may influence outcome parameters, which should be taken as a whole. The large cohort and long-term outcome, which contribute to the strength of analysis and statements serving as a major strength, also serve to increase heterogeneity of the cohort. The radiosurgical device, imaging, and software used are subject to change. From a procedural point of view, radiosurgical technology and treatment algorithms have been refined over the study period, and this could have contributed to a bias. However, despite these ongoing quality assurance and technical modifications, no significant difference in the outcome parameters over time was noted. Finally, the extent of generality of our results is not clear, and the results may reflect added experience seen at a tertiary center with appreciable SRS experience.

\section{Conclusions}

Stereotactic radiosurgery is a durable and minimally invasive option for the treatment of benign parasellar meningiomas. High rates of tumor growth control can be accomplished via SRS with an acceptably low incidence of neurological deficits and related neuropathies compared with other treatment modalities for meningiomas in this challenging region. Lesion volumetric regression or stability in relatively short-term follow-up of 3 years after SRS was shown to be predictive of long-term tumor control.

\section{References}

1. Arnautović KI, Al-Mefty O, Husain M: Ventral foramen magnum meningiomas. J Neurosurg (Spine 1) 92:71-80, 2000

2. Bassiouni H, Asgari S, Stolke D: Tuberculum sellae meningiomas: functional outcome in a consecutive series treated microsurgically. Surg Neurol 66:37-45, 2006

3. Cavallo LM, Cappabianca P, Galzio R, Iaconetta G, de Divitiis E, Tschabitscher M: Endoscopic transnasal approach to the cavernous sinus versus transcranial route: anatomic study. Neurosurgery 56 (2 Suppl):379-389, 2005

4. Chang SD, Adler JR Jr: Treatment of cranial base meningiomas with linear accelerator radiosurgery. Neurosurgery 41:1019-1027, 1997

5. Chi JH, McDermott MW: Tuberculum sellae meningiomas. Neurosurg Focus 14(6): e6, 2003

6. Cohen-Inbar O, Lee CC, Schlesinger D, Xu Z, Sheehan JP: The Geriatric Scoring System (GSS) for risk stratification in meningioma patients as a predictor of outcome in patients treated with radiosurgery. World Neurosurg 87:431-438, 2016

7. Cohen-Inbar O, Lee CC, Schlesinger D, Xu Z, Sheehan JP: Long-term results of stereotactic radiosurgery for skull base meningiomas. Neurosurgery 79:58-68, 2016

8. Cohen-Inbar O, Lee CC, Sheehan JP: The contemporary role of stereotactic radiosurgery in the treatment of meningiomas. Neurosurg Clin N Am 27:215-228, 2016

9. Deltour I, Johansen C, Auvinen A, Feychting M, Klaeboe $\mathrm{L}$, Schüz J: Time trends in brain tumor incidence rates in Denmark, Finland, Norway, and Sweden, 1974-2003. J Natl Cancer Inst 101:1721-1724, 2009

10. DiBiase SJ, Kwok Y, Yovino S, Arena C, Naqvi S, Temple $\mathrm{R}$, et al: Factors predicting local tumor control after Gamma Knife stereotactic radiosurgery for benign intracranial meningiomas. Int J Radiat Oncol Biol Phys 60:1515-1519, 2004

11. Duma CM, Lunsford LD, Kondziolka D, Harsh GR IV, Flickinger JC: Stereotactic radiosurgery of cavernous sinus meningiomas as an addition or alternative to microsurgery. Neurosurgery 32:699-705, 1993

12. Eustacchio S, Trummer M, Fuchs I, Schröttner O, Sutter $\mathrm{B}$, Pendl G: Preservation of cranial nerve function following Gamma Knife radiosurgery for benign skull base meningiomas: experience in 121 patients with follow-up of 5 to 9.8 years. Acta Neurochir Suppl 84:71-76, 2002

13. Feigl GC, Samii M, Horstmann GA: Volumetric follow-up of meningiomas: a quantitative method to evaluate treatment outcome of Gamma Knife radiosurgery. Neurosurgery 61:281-287, 2007

14. Flickinger JC, Kondziolka D, Maitz AH, Lunsford LD: Gamma Knife radiosurgery of imaging-diagnosed intracranial meningioma. Int J Radiat Oncol Biol Phys 56:801-806, 2003

15. Fokas E, Henzel M, Surber G, Hamm K, Engenhart-Cabillic $\mathrm{R}$ : Stereotactic radiation therapy for benign meningioma: long-term outcome in 318 patients. Int J Radiat Oncol Biol Phys 89:569-575, 2014

16. Ganz JC, Reda WA, Abdelkarim K: Gamma Knife surgery of large meningiomas: early response to treatment. Acta Neurochir (Wien) 151:1-8, 2009

17. Han JH, Kim DG, Chung HT, Park CK, Paek SH, Kim CY, et al: Gamma Knife radiosurgery for skull base meningiomas: long-term radiologic and clinical outcome. Int J Radiat Oncol Biol Phys 72:1324-1332, 2008

18. Hasegawa T, Kida Y, Yoshimoto M, Koike J, Iizuka H, Ishii D: Long-term outcomes of Gamma Knife surgery for cavernous sinus meningioma. J Neurosurg 107:745-751, 2007

19. Henzel M, Gross MW, Hamm K, Surber G, Kleinert G, Failing T, et al: Significant tumor volume reduction of meningiomas after stereotactic radiotherapy: results of a prospective multicenter study. Neurosurgery 59:1188-1194, 2006

20. Hudgins WR, Barker JL, Schwartz DE, Nichols TD: Gamma 
Knife treatment of 100 consecutive meningiomas. Stereotact Funct Neurosurg 66 (1 Suppl 1):121-128, 1996

21. Ichinose T, Goto T, Ishibashi K, Takami T, Ohata K: The role of radical microsurgical resection in multimodal treatment for skull base meningioma. J Neurosurg 113:1072-1078, 2010

22. Igaki H, Maruyama K, Koga T, Murakami N, Tago M, Terahara A, et al: Stereotactic radiosurgery for skull base meningioma. Neurol Med Chir (Tokyo) 49:456-461, 2009

23. Iwai Y, Yamanaka K, Ikeda H: Gamma Knife radiosurgery for skull base meningioma: long-term results of low-dose treatment. J Neurosurg 109:804-810, 2008

24. Iwai Y, Yamanaka K, Ishiguro T: Gamma Knife radiosurgery for the treatment of cavernous sinus meningiomas. Neurosurgery 52:517-524, 2003

25. Jääskeläinen J: Seemingly complete removal of histologically benign intracranial meningioma: late recurrence rate and factors predicting recurrence in 657 patients. A multivariate analysis. Surg Neurol 26:461-469, 1986

26. Kimball MM, Friedman WA, Foote KD, Bova FJ, Chi YY: Linear accelerator radiosurgery for cavernous sinus meningiomas. Stereotact Funct Neurosurg 87:120-127, 2009

27. Kondziolka D, Mathieu D, Lunsford LD, Martin JJ, Madhok $R$, Niranjan A, et al: Radiosurgery as definitive management of intracranial meningiomas. Neurosurgery 62:53-60, 2008

28. Kreil W, Luggin J, Fuchs I, Weigl V, Eustacchio S Papaefthymiou G: Long term experience of Gamma Knife radiosurgery for benign skull base meningiomas. J Neurol Neurosurg Psychiatry 76:1425-1430, 2005

29. Lee JY, Niranjan A, McInerney J, Kondziolka D, Flickinger JC, Lunsford LD: Stereotactic radiosurgery providing longterm tumor control of cavernous sinus meningiomas. J Neurosurg 97:65-72, 2002

30. Linskey ME, Davis SA, Ratanatharathorn V: Relative roles of microsurgery and stereotactic radiosurgery for the treatment of patients with cranial meningiomas: a singlesurgeon 4-year integrated experience with both modalities. J Neurosurg 102 Suppl:59-70, 2005

31. Liscák R, Simonová G, Vymazal J, Janousková L, Vladyka V: Gamma Knife radiosurgery of meningiomas in the cavernous sinus region. Acta Neurochir (Wien) 141:473-480, 1999

32. Morita A, Coffey RJ, Foote RL, Schiff D, Gorman D: Risk of injury to cranial nerves after Gamma Knife radiosurgery for skull base meningiomas: experience in 88 patients. $\mathbf{J}$ Neurosurg 90:42-49, 1999

33. Natarajan SK, Sekhar LN, Schessel D, Morita A: Petroclival meningiomas: multimodality treatment and outcomes at long-term follow-up. Neurosurgery 60:965-981, 2007

34. Nicolato A, Foroni R, Alessandrini F, Maluta S, Bricolo A, Gerosa M: The role of Gamma Knife radiosurgery in the management of cavernous sinus meningiomas. Int J Radiat Oncol Biol Phys 53:992-1000, 2002

35. Nicolato A, Foroni R, Pellegrino M, Ferraresi P, Alessandrini F, Gerosa M, et al: Gamma Knife radiosurgery in meningiomas of the posterior fossa. Experience with 62 treated lesions. Minim Invasive Neurosurg 44:211-217, 2001

36. Parkinson D: Lateral sellar compartment: history and anatomy. J Craniofac Surg 6:55-68, 1995

37. Pollock BE, Flickinger JC: Modification of the radiosurgerybased arteriovenous malformation grading system. Neurosurgery 63:239-243, 2008

38. Pollock BE, Stafford SL: Results of stereotactic radiosurgery for patients with imaging defined cavernous sinus meningiomas. Int J Radiat Oncol Biol Phys 62:1427-1431, 2005

39. Pollock BE, Stafford SL, Utter A, Giannini C, Schreiner SA: Stereotactic radiosurgery provides equivalent tumor control to Simpson Grade 1 resection for patients with small- to medium-size meningiomas. Int J Radiat Oncol Biol Phys 55:1000-1005, 2003

40. Roberti F, Sekhar LN, Kalavakonda C, Wright DC: Posterior fossa meningiomas: surgical experience in 161 cases. Surg Neurol 56:8-21, 2001

41. Roche PH, Régis J, Dufour H, Fournier HD, Delsanti $\mathrm{C}$, Pellet W, et al: Gamma Knife radiosurgery in the management of cavernous sinus meningiomas. J Neurosurg 93 (Suppl 3):68-73, 2000

42. Selch MT, Ahn E, Laskari A, Lee SP, Agazaryan N, Solberg TD, et al: Stereotactic radiotherapy for treatment of cavernous sinus meningiomas. Int J Radiat Oncol Biol Phys 59:101-111, 2004

43. Sheehan J, Pan HC, Stroila M, Steiner L: Gamma Knife surgery for trigeminal neuralgia: outcomes and prognostic factors. J Neurosurg 102:434-441, 2005

44. Sheehan JP, Starke RM, Kano H, Kaufmann AM, Mathieu D, Zeiler FA, et al: Gamma Knife radiosurgery for sellar and parasellar meningiomas: a multicenter study. J Neurosurg 120:1268-1277, 2014

45. Shin M, Kurita H, Sasaki T, Kawamoto S, Tago M, Kawahara $\mathrm{N}$, et al: Analysis of treatment outcome after stereotactic radiosurgery for cavernous sinus meningiomas. J Neurosurg 95:435-439, 2001

46. Simpson D: The recurrence of intracranial meningiomas after surgical treatment. J Neurol Neurosurg Psychiatry 20:22-39, 1957

47. Skeie BS, Enger PO, Skeie GO, Thorsen F, Pedersen PH: Gamma Knife surgery of meningiomas involving the cavernous sinus: long-term follow-up of 100 patients. Neurosurgery 66:661-669, 2010

48. Snell JW, Sheehan J, Stroila M, Steiner L: Assessment of imaging studies used with radiosurgery: a volumetric algorithm and an estimation of its error. Technical note. J Neurosurg 104:157-162, 2006

49. Spiegelmann R, Cohen ZR, Nissim O, Alezra D, Pfeffer R: Cavernous sinus meningiomas: a large LINAC radiosurgery series. J Neurooncol 98:195-202, 2010

50. Spiegelmann R, Nissim O, Menhel J, Alezra D, Pfeffer MR: Linear accelerator radiosurgery for meningiomas in and around the cavernous sinus. Neurosurgery 51:1373-1380, 2002

51. Stafford SL, Pollock BE, Foote RL, Link MJ, Gorman DA, Schomberg PJ, et al: Meningioma radiosurgery: tumor control, outcomes, and complications among 190 consecutive patients. Neurosurgery 49:1029-1038, 2001

52. Starke RM, Williams BJ, Hiles C, Nguyen JH, Elsharkawy MY, Sheehan JP: Gamma Knife surgery for skull base meningiomas. J Neurosurg 116:588-597, 2012

53. Sughrue ME, Kane AJ, Shangari G, Rutkowski MJ, McDermott MW, Berger MS, et al: The relevance of Simpson Grade I and II resection in modern neurosurgical treatment of World Health Organization Grade I meningiomas. J Neurosurg 113:1029-1035, 2010

54. Sughrue ME, Rutkowski MJ, Aranda D, Barani IJ, McDermott MW, Parsa AT: Factors affecting outcome following treatment of patients with cavernous sinus meningiomas. J Neurosurg 113:1087-1092, 2010

55. Surawicz TS, McCarthy BJ, Kupelian V, Jukich PJ, Bruner JM, Davis FG: Descriptive epidemiology of primary brain and CNS tumors: results from the Central Brain Tumor Registry of the United States, 1990-1994. Neuro Oncol 1:14-25, 1999

56. Takanashi M, Fukuoka S, Hojyo A, Sasaki T, Nakagawara J, Nakamura H: Gamma Knife radiosurgery for skull-base meningiomas. Prog Neurol Surg 22:96-111, 2009

57. Tishler RB, Loeffler JS, Lunsford LD, Duma C, Alexander E III, Kooy HM, et al: Tolerance of cranial nerves of the 
cavernous sinus to radiosurgery. Int J Radiat Oncol Biol Phys 27:215-221, 1993

58. Williams BJ, Yen CP, Starke RM, Basina B, Nguyen J, Rainey J, et al: Gamma Knife surgery for parasellar meningiomas: long-term results including complications, predictive factors, and progression-free survival. J

Neurosurg 114:1571-1577, 2011

\section{Disclosures}

The authors report no conflict of interest concerning the materials or methods used in this study or the findings specified in this paper.

\section{Author Contributions}

Conception and design: Cohen-Inbar, Sheehan. Acquisition of data: Cohen-Inbar, Tata, Moosa. Analysis and interpretation of data: Cohen-Inbar. Drafting the article: Cohen-Inbar. Critically revising the article: Cohen-Inbar, Tata, Moosa, Sheehan. Reviewed submitted version of manuscript: Cohen-Inbar, Lee, Sheehan. Approved the final version of the manuscript on behalf of all authors: CohenInbar. Statistical analysis: Lee. Administrative/technical/material support: Sheehan. Study supervision: Sheehan.

\section{Correspondence}

Or Cohen-Inbar, Department of Neurological Surgery, University of Virginia Health System, Box 800212, Charlottesville, VA 22908.email: oc2f@virginia.edu. 